\title{
Knowledge, Attitude and Practice towards Osteoporosis among General Practitioners Working in Al Majmaah Province, KSA
}

\author{
Zaheer Ahmed ${ }^{1 *}$, Daifallah Alharbi', Abdul Lateef Junaid ${ }^{2}$, Riyaz Ahamed Shaik ${ }^{3}$ \\ and Waqas Sami ${ }^{3}$ \\ 'Department of Orthopaedics, College of Medicine, Al Majmaah University, Al Majmaah - 11952, \\ Saudi Arabia; z.mohammed@mu.edu.sa, d.alharbi@mu.edu.sa \\ 2Department of Pathology, College of Medicine, Al Majmaah University, Al Majmaah - 11952, \\ Saudi Arabia; m.junaid@mu.edu.sa, r.shaik@mu.edu.sa \\ ${ }^{3}$ Department of Community Medicine and Public Health, College of Medicine, Al Majmaah \\ University, Al Majmaah - 11952, Saudi Arabia; biostatistician1@gmail.com
}

\begin{abstract}
Background: Osteoporosis is the most common metabolic disorder affecting bone which develops because of normal ageing, excessive bone loss during adulthood and impaired development of peak bone mass. Awareness among physicians is vital for the early detection and timely treatment and hence fractures prevention. The present study was carried out to study the knowledge, attitude and practice towards osteoporosis among general practitioners working in Al Majmaah, KSA. Methodology: This crosssectional research was conducted among all the qualified family physicians, general practitioners and resident doctors in Majmaah province, KSA. Data collection was done based on a standardized KAP questionnaire. Results: All the data were entered and analysed according to the intentions of the present work. Good level of knowledge concerning the diagnosis was observed among the study subjects and a high proportion of respondents believed in the preventive strategies of the disease. Responses were obtained from total of 43 practitioners who included $23.3 \%$ female, and $76.7 \%$ male in and around Majmaah province. Majority (72.1\%) of the respondent's attitude was that osteoporosis has major effect on the health of the community. In relation to practice aspects, prescription of $76.7 \%$ responders includes bisphosphonates as the most commonly used drug for treatment of osteoporosis. Conclusion: A considerable level of knowledge and positive attitude towards osteoporosis was found; however, practices for the prevention of osteoporosis still need improvement. There is a need to extend the medical knowledge of general practitioners in Al Majmaah Province, KSA, regarding the contemporary management of osteoporosis and its risk factors. Professional training programs are required to enhance the practitioner's knowledge and attitude to improve their practices.
\end{abstract}

Keywords: Al-Majmaah, General Practitioners, Osteoporosis, Prevention

\section{Introduction}

Osteoporosis (OP) is a silent killer in geriatric group as this could lead to fragility fractures and later to high mortality and morbidity. Though osteoporosis is a chronic and progressive disease, it is relatively preventable and well-treatable at primary level. General practitioners at PHC (Primary Health Centre), family physicians and also resident doctors being the most relevant health care professionals when it comes to diagnosing and treating the common diseases and more importantly, they play a vital role in releasing the burden of care on health system. Communication among healthcare professionals and patients enhances the management of this condition and also educating the community for its prevention.

Osteoporosis is the common metabolic bone disorder worldwide. This entity is preventable and treatable if detected at initial stages. Osteoporosis is assessed to 
affect over 200 million people globally. The prevalence of osteoporosis in Saudi Arabia among age group 50-80 years is estimated to be $34-39.5 \%$ in women and $21.4-$ $30.7 \%$ in healthy men ${ }^{1}$. Some epidemiological analysis exhibited that $34 \%$ of healthy Saudi women, and $30.7 \%$ of men, aged 50-79 years are suffering from osteopororsis ${ }^{2}$. Hence this being the most common metabolic bone disorder in both sexes of population, patients will first approach the general practitioners or the family physician or the resident doctors for consultation. In Saudi Arabia very few works have been done in sub urban and rural region about the knowledge, attitude, and practice of this condition.

Hence, the need for this research is to know the knowledge, attitude and practice of health care providers about this disease condition together in the suburban and rural areas. Thus, our study is in accordance with the mission of Saudi osteoporosis society that is to improve patient care in the field of osteoporosis through evidencebased learning, expert analysis, and Case-study based management. It is anticipated that, by 2050, the hip fracture global incidence is projected to enhance by $310 \%$ in men and $240 \%$ in women respectively, compared to rates in $1990^{3}$. Osteoporosis is anticipated to affect 200 million women roughly two-thirds of women aged 90 , two-fifths of women aged 80, one-fifth of women aged 70 , and one-tenth of women aged 60 causing more than 8.9 million fractures yearly, that roughly estimates an osteoporotic fracture in every 3 seconds ${ }^{4,5}$.

An International Osteoporosis Foundation survey was conducted in 11 countries, the result of which showed denial of personal risk by postmenopausal women, lack of dialogue concerning osteoporosis with their doctors, and limited access to diagnosis and treatment before the initial fracture leads to under diagnosis and under treatment of such disease ${ }^{6}$. Osteoporosis medications lower the chance of fracture, but they do not eliminate all risk of bone fracture. Identifying and treating patients at risk of fracture, but who have not yet sustained a fracture, will substantially reduce the long term burden of osteoporosis. First fracture risk reduction from $8 \%$ to $2 \%$ can reduce the 5 -year fracture incidence from roughly $34 \%$ to $10 \%{ }^{7}$. It was found that more than $80 \%$ of participants had good knowledge about osteoporosis risk factors in a study done in Saudi Arabia ${ }^{8,9}$.

A study identified gaps in knowledge of physicians about bone health in Saudi Arabia. There is a requirement to extend medical knowledge concerning the osteoporosis contemporary management and risk aspects associated to it. The outcome of the knowledge, attitude and practice study can be used for improving physicians' performance; hence it has to be executed on regular basis as part of the prevention strategy of osteoporosis ${ }^{10}$. KAP studies can be used for evaluating the requirements, difficulties and barriers among health care program, and also solutions for improving quality and accessibility of services. Hence, the present study was undertaken to evaluate the "Knowledge, Attitude, and Practice towards osteoporosis among general practitioners working in Majmaah province, KSA".

\section{Methodology}

The cross sectional research was conducted among all the general practitioners and resident level doctors who working in hospitals and primary healthcare centres in Al' Majmaah province, KSA. The duration of the study was six months (from September 2018 - March 2019). The sampling of the study was done by 'Complete enumeration method'. All medical practitioners, both males and females of King Khalid general hospital and of PHCs in and around Al Majmaah city were selected as participants. The sample size was calculated based on previous published research which had a similar number $(n=40)$ of study participants ${ }^{8}$. About 43 participants were selected for the study in these 33 was males and 10 females. Informed consent was taken from each practitioner at the time of distributing the questionnaire. The practitioners were informed about the confidentiality of the data, that it will be utilized only for the purpose of this study. Respondents who have given verbal consent were also included in the study. The practitioners who were not willing to participate were excluded from the study.

The participants were contacted and the study was conducted during the academic year 2018-19. Data collection was done by pre-tested and self-administered questionnaire (Annexure I). A general questionnaire was developed to gather information from the participants about their knowledge, attitude and practice towards osteoporosis. The socio-demographic and professional questionnaire includes data on the practitioner's age, gender, years of experience, nationality and place of work. Practitioners were asked about their knowledge on plain $\mathrm{X}$-ray radiography, bisphosphonates, oral calcium and vitamins intake in osteoporosis. 
Attitude of practitioners towards the impact of osteoarthritis, osteoporosis, coronary heart disease, cerebrovascular disease, diabetes mellitus, vitamin D deficiency etc. were assessed.

The practice related questions about family history of bone fracture, back pain, osteoarthritis, calcium intake, post-menopausal, physical exercise, first line of pharmacological treatment in majority of patients with osteoporosis, bone mineral density and biochemical marker testing were taken into consideration.

\subsection{Inclusion Criteria}

Family physicians, General practitioners and Resident doctors (MBBS Graduates).

\subsection{Exclusion Criteria}

Specialist's doctors, consultants (Post Graduates), general practitioners and resident level doctors working outside Al Majmaah region, KSA were excluded from the study.

\subsection{Ethical Clearance}

All procedures for the present study were approved by Institutional Review Board of King Fahad Medical City, KSA (IRB-18-180E). Participation in the study was voluntary and practitioner's consent was taken before they completed the questionnaire.

\section{Statistical Analysis}

The data was entered and analysed using IBM SPSS Statistics for Windows, Version 25.0. Armonk, NY: IBM Corp. Frequencies and percentages are reported for qualitative variables. Mean scores were calculated for attitude sub-groups. Values above the mean were considered as having positive attitude, whereas, values below the mean were considered as having negative attitude. Pearson-chi square and Fisher Exact test were applied to observe the association between the knowledge, attitude and practice variables and demographic variables. A p-value of $<0.05$ was considered as statistically significant.

\section{Results}

A total 43 completed questionnaires were incorporated for the final assessment. The respondents age ranged between 24 and 59 years with a mean of 41.5 years, about three fourth of the samples were males $(76.7 \%)$ in that the majority of the physicians were non-Saudis (93\%). Regarding the professional data; a greater number of doctors were working in PHCs $46.5 \%, 14 \%$ in hospitals and about $39.5 \%$ were family physicians and general practitioners working in university clinics with an average experience time of 11.7 years (Table 1). Furthermore, for sources of knowledge; nearly all respondents (74.4\%) reported to have good level of knowledge and only few people have poor knowledge towards osteoporosis (25.6\%) (Figure1).

A score of $<50 \%$ was considered as having poor knowledge, whereas, a score between $50 \%-75 \%$ was considered as having a good knowledge and a score $>75 \%$ was considered as having adequate knowledge ${ }^{11}$.

With respect to radiological methods for osteoporosis screening and diagnosis; most of the responders (53.3\%) were aware of plain X-ray usage and fracture prediction, but $46.5 \%$ were not aware about predicting fractures (Figure 2).

The participant's attitude toward OP prevention and management is depicted in (Table 2). Depending upon Table 1. Socio-demographic and professional characteristics of the participating physicians

\begin{tabular}{|c|c|c|c|}
\hline \multicolumn{4}{|c|}{ Number of Responders $=43$} \\
\hline \multirow{2}{*}{ Age in years } & \multirow{2}{*}{$\begin{array}{l}\text { Mean } \pm \text { SD } \\
\text { Range }\end{array}$} & \multicolumn{2}{|c|}{$41.5 \pm 4.80$} \\
\hline & & \multicolumn{2}{|c|}{$24-59$} \\
\hline \multirow{2}{*}{$\begin{array}{c}\text { Years of } \\
\text { Experience }\end{array}$} & \multirow{3}{*}{$\begin{array}{c}\text { Mean } \pm \text { SD } \\
\text { Range }\end{array}$} & \multicolumn{2}{|c|}{$11.7 \pm 4.80$} \\
\hline & & \multicolumn{2}{|c|}{$1-35$} \\
\hline & & Frequency & Percentage \\
\hline \multirow{2}{*}{ Sex } & Male & 33 & $76.7 \%$ \\
\hline & Female & 10 & $23.3 \%$ \\
\hline \multirow{2}{*}{ Nationality } & Saudi & 3 & $7.0 \%$ \\
\hline & Non Saudi & 40 & $93.0 \%$ \\
\hline \multirow{3}{*}{ Place of work } & $\begin{array}{c}\text { Doctors in } \\
\text { Hospital }\end{array}$ & 6 & $14 \%$ \\
\hline & $\begin{array}{l}\text { Doctors in } \\
\text { PHC }\end{array}$ & 20 & $46.5 \%$ \\
\hline & $\begin{array}{c}\text { Doctors in } \\
\text { University } \\
\text { clinics }\end{array}$ & 17 & $39.5 \%$ \\
\hline
\end{tabular}

PHC- Primary Health Centre 


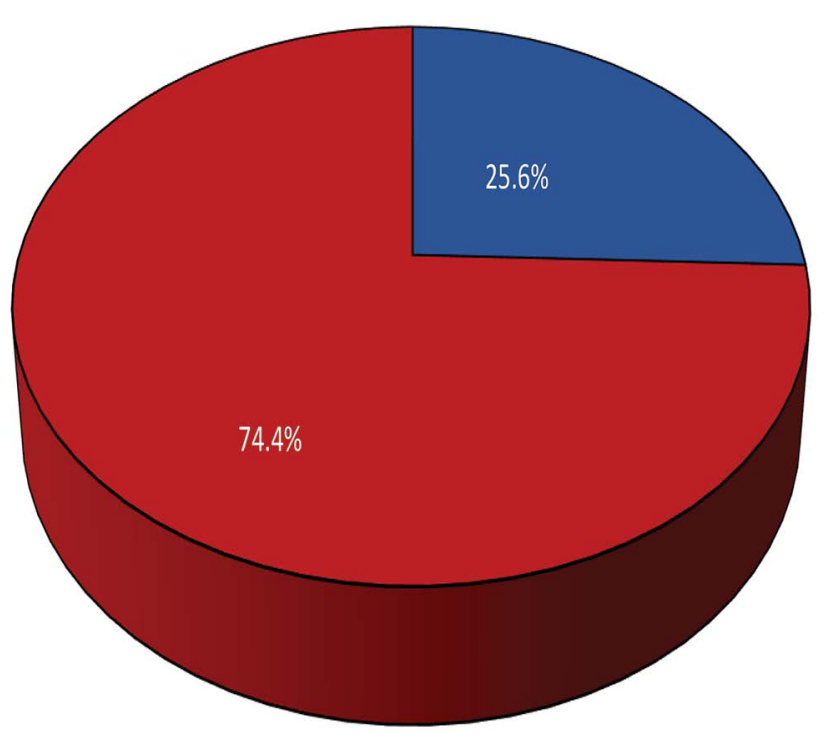

DPoor Knowledge DExcellent Knowledge

Figure 1. Frequency of responses for presence of osteoporosis knowledge sources.

Table 2. Attitude towards OP among PHC physicians

\begin{tabular}{|l|c|}
\hline \multicolumn{2}{|c|}{ Percentage (95\% CI) ${ }^{*}$} \\
\hline \multicolumn{2}{|c|}{$\begin{array}{c}\text { Impact of the following diseases on health of the } \\
\text { community and individuals? }\end{array}$} \\
\hline Osteoarthritis & 54 \\
\hline Osteoporosis & 72.1 \\
\hline Coronary heart disease & 88.4 \\
\hline Diabetes mellitus & 74 \\
\hline Cerebrovascular diseases & 72 \\
\hline Post-menopausal Female & 86.1 \\
\hline Lack of physical exercise & 72.1 \\
\hline Poor calcium diet & 70.4 \\
\hline Vitamin D deficiency & 86.1 \\
\hline Hormone replacement therapy & 62.8 \\
\hline Calcium supplementation & 72.1 \\
\hline Vitamin D supplementation & 86 \\
\hline Regular physical exercise & 74.5 \\
\hline
\end{tabular}

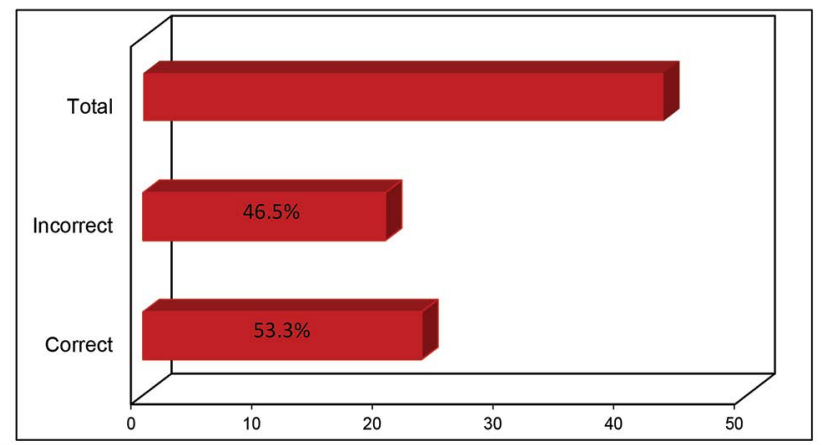

Figure 2. Knowledge regarding plain radiography.

the severity of disease impact, the present study phase included a grading system. Majority $(72.1 \%)$ of the responders thought that osteoporosis has major effect on the health of the community, whereas $54 \%$ of participants believed that there is high impact of osteoarthritis on the health of individuals. Responders believe that diabetes mellitus (74.8\%), cerebrovascular disease (72.1\%), menopause (86.1\%), coronary heart disease $(88.4 \%)$, and lack of exercise $(72.1 \%)$ can also lead to severe impact on individual heath. In respect to the risk aspects, $62.8 \%$ physicians believe that osteoporosis have severe impact on human health.

86.1\% responders assume that post-menopausal females can be at risk whereas $74.4 \%$ believe that poor calcium diet can leads to severe impact of the disease. Respecting the principles of preventive strategies; respondents place confidence with high rates in most of the osteoporosis preventive measures to administer hormonal therapy to particular subjects $(62.8 \%)$. The study subjects believe that calcium intake $(72.1 \%)$, vitamin supplementation $(86 \%)$ and regular exercise $(74.5 \%)$ were found to be an effective means to stimulate osteogenesis in osteoporotic patients.

Table 3 shows the participants' responses in respect to practices of osteoporosis management. With respect to the history taking practices; $90.7 \%$ practitioners inquire concerning back pain, daily calcium intake, and current cigarette smoking. About $83.7 \%$ of the practitioners analysed the history of fracture whereas $86 \%$ of the practitioners enquire about the history of osteoporosis. Regarding examination of cases; around $81.4 \%$ of the respondents reported that they examine their patients for kyphosis, loss of height (67.4\%) and loss of weight (74.4\%). For the main tools of investigations; only $11.6 \%$ declared that they have access to perform Bone Mineral 
Density (BMD) and only $27.9 \%$ can ask for biochemical marking testing for their clients.

Table 3. Practice of physicians regarding OP management

\begin{tabular}{|l|c|}
\hline \multicolumn{2}{|c|}{ Percentage (95\% Confidence Interval) } \\
\hline $\begin{array}{l}\text { WHO criteria define osteoporosis as T score less than 2.5 SD } \\
9090.2 \text { (86.3-93.7) }\end{array}$ \\
\hline \multicolumn{2}{|c|}{ How often do you ask about the following? } \\
\hline Back pain & 90.7 \\
\hline Fracture History & 83.7 \\
\hline History of Osteoporosis & 86 \\
\hline Smoking & 90.7 \\
\hline Daily Calcium intake & 90.7 \\
\hline \multicolumn{1}{|c|}{ How do you often look for the following in your } \\
\hline Kyphosis & 81.4 \\
\hline Loss of height & 67.4 \\
\hline Low body weight & 74.4 \\
\hline $\begin{array}{l}\text { Do you have access to perform Bone Mineral } \\
\text { Density }\end{array}$ & 11.6 \\
\hline $\begin{array}{l}\text { Do you have access to biochemical marker testing } \\
\text { of bone? }\end{array}$ & 27.9 \\
\hline $\begin{array}{l}\text { Having any subscription in any medical journal or } \\
\text { website? }\end{array}$ & 25.6 \\
\hline
\end{tabular}

In relation to bisphosphonates as treatment remedy, $76.7 \%$ were aware that it is the most commonly used drug for treatment of osteoporosis. Moreover, 2.3\% of responders believe that Vitamin $\mathrm{D}$ and $\mathrm{K}$ can be used for preventing the disease. $20.9 \%$ of the physicians were aware about oral calcium supplementation in osteoporosis (Figure 3).

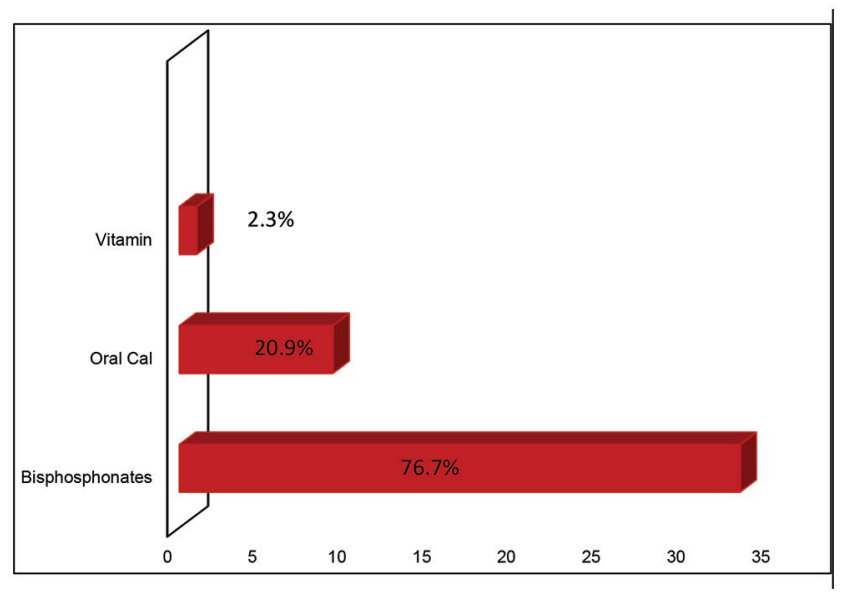

Figure 3. Knowledge regarding bisphosphonates, oral calcium and vitamins intake.
As for online subscription in medical journal, only $25 \%$ of responders declared to have subscription in medical journal online.

\section{Discussion}

Osteoporosis is considered to be the most common bone disease afflicting humans ${ }^{12}$. More than 200 million women are affected annually worldwide. The economic impact of osteoporotic fractures is large and growing ${ }^{13}$. Osteoporosis can be disabling and limit patient's physical activity. The complications of osteoporosis can be lifethreatening in elderly people. The level of knowledge, attitude and practice of health care provider are important factors in the prevention and control of all chronic diseases and osteoporosis is not an exception. The current study was done to evaluate the level of "knowledge, attitude and practice among general practitioners working in $\mathrm{Al}$ Majmaah province, KSA".

A convenience sampling technique was selected for recruiting the participants and self-administered questionnaire was used. Bone texture characterization is vital in diagnosing and treating osteoporosis ${ }^{14}$ since only $53.3 \%$ of study subjects had knowledge on plain radiography. Hormonal replacement therapy was found to be very effective for preventing osteoporosis. Similarly, in relation to the study of Jiang et al. (2018) 14 reported that the majority of the physicians agreed that hormonal replacement therapy can be taken as an effective tool in preventing osteoporosis. Vitamin $\mathrm{D}$, vitamin $\mathrm{K}$ and calcium is being considered vital for the treatment and prevention of osteoporosis ${ }^{15}$. Recently, the usefulness of calcium supplementation has been emphasised, where as some studies reported only weak efficacy of these supplementations in reducing fragility fracture risk ${ }^{16}$.

Only $2.3 \%$ practitioners of the total responders had an opinion that Vitamin D is solely effective in the treatment of osteoporosis. Significant association of awareness level was noted with socio-demographic determinants.

For the participant's attitude towards osteoporosis prevention and management, the majority of participants believed that osteoporosis has major impact on the health of individuals as well as the community in comparison with osteoarthritis with the percentage being $72 \%$ and $54 \%$, respectively. This was in agreement with the Iranian study which noticed that only $30 \%$ did not consider osteoporosis as an important health problem ${ }^{17}$. 
Bisphosphonates are dominant inhibitors of osteoclastmediated bone resorption; therefore, these are mainly used in treating Osteoporosis ${ }^{18}$. About $57.6 \%$ of the study subjects had knowledge about bisphosphonates in the present study. Physician's awareness of bisphosphonates related side effects can potentially lead to prevent the occurrence of more serious complications due to an earlier detection and management. It can also increase the safety of a therapy proven to be effective to numerous patients.

\section{Limitations of this Study}

The study reports are limited to the King Khalid general hospital and primary healthcare centres in and around Al Majmaah, KSA. The selection bias may be a major limitation of this study as only the medical practitioners who were willing to be a part of the study were included.

\section{Conclusion}

A considerable level of knowledge and positive attitudes towards osteoporosis was found; however, practices for the prevention of osteoporosis still need improvement. Professional training programs are required to enhance the practitioner's knowledge so as to improve their practices. It is vital for the Ministry of Health to disseminate the updated clinical practice guidelines to all the general practitioners working at primary and secondary care levels. Therefore, the study recommends that health authorities must have better participation in patient education efforts to maintain proper standards of care. The obvious gap among the osteoporosis preventionrelated knowledge, attitude and practice needs innovative strategies based on local evidence to promote and encourage adoption and practice of personal protective measures.

\section{Source of funding}

None

\section{Conflict of Interest}

No potential conflict of interest was reported by the authors.

\section{Acknowledgement}

We are thankful to the Deanship of Scientific Research, Majmaah University, KSA for giving us the opportunity to conduct this research. We also thank all the medical practitioner of King Khalid general hospital and primary healthcare centres in and around Al Majmaah city, KSA, and all the people who took part in this study.

\section{References}

1. Khan JA, McGuigan FE, Akesson KE, Ahmed YM, Abdu F, Rajab H, et al. Osteoporosis knowledge and awareness among university students in Saudi Arabia. Archives of Osteoporosis. 2019; 14(1):8. https://doi.org/10.1007/ s11657-019-0560-y. PMid: 30644020.

2. Sadat-Ali M, Al-Habdan IM, Al-Turki HA, Azam MQ. An epidemiological analysis of the incidence of osteoporosis and osteoporosis-related fractures among the Saudi Arabian population. Annals of Saudi Medicine. 2012; 32(6):637-41. https://doi.org/10.5144/0256-4947.2012.637. PMid: 23396029, PMCid: PMC6081105.

3. Gullberg B, Johnell O, Kanis JA. World-wide projections for hip fracture. Osteoporosis International. 1997; 7(5):407-13. https://doi.org/10.1007/PL00004148. PMid: 9425497.

4. Kanis JA, McCloskey E, Johansson H, Oden A, Leslie WD. FRAX ${ }^{\otimes}$ with and without bone mineral density. Calcified Tissue International. 2012; 90(1):1-3. https://doi. org/10.1007/s00223-011-9544-7. PMid: 22057815.

5. Johnell O, Kanis JA. An estimate of the worldwide prevalence and disability associated with osteoporotic fractures. Osteoporosis International. 2006; 17(12):172633. https://doi.org/10.1007/s00198-006-0172-4. PMid: 16983459.

6. Kanis JA, Black D, Cooper C, Dargent P, Dawson-Hughes B, De Laet C, et al. A new approach to the development of assessment guidelines for osteoporosis. Osteoporosis International. 2002; 13(7): 527-36. https://doi.org/10.1007/ s001980200069. PMid: 12111012.

7. Lindsay R, Pack S, Li Z. Longitudinal progression of fracture prevalence through a population of postmenopausal women with osteoporosis. Osteoporosis International. 2005; 16(3):306-12. https://doi.org/10.1007/s00198-0041691-5. PMid: 15455193.

8. Saeedi MY, Al-Amri F, Mohamed A, Ibrahim AK. Knowledge, attitude and practice towards osteoporosis among primary health care physicians in Riyadh, Saudi Arabia. Sci. J. Public Heal. 2014; 2(6):624-30.

9. Al-Musa H, Alassmi M, AlMoria A, Alghamdi H, Alfaifi S. Knowledge, practice and barriers in management of Osteoporosis. Biomedical Research. 2013; 24(4):429-34. 
10. Saeedi MY, Al-Amri F, Mohamed A, Ibrahim AK. Knowledge, attitude and practice towards osteoporosis among primary health care physicians in Riyadh, Saudi Arabia. Sci. J. Public Heal. 2014; 2(6):624-30.

11. Waqas Sami, et al. Diabetes mellitus knowledge of type 2 diabetic patients, Almajmaah, Saudi Arabia. International Journal of Advanced Life Sciences (IJALS). November 2017; 10(4):377-85. https://pdfs.semanticscholar.org/d646 /4ccd0f7f0273e1ddfdc9eeeb4d500ea58a6b.pdf.

12. Kanis JA. Diagnosis and Clinical Aspects of Osteoporosis. In: Pocket Reference to Osteoporosis; 2019. p. 11-20. https://doi.org/10.1007/978-3-319-26757-9_2.

13. Hiligsmann M, Reginster JY, Tosteson AN, Bukata SV, Saag $\mathrm{KG}$, Gold DT, et al. Recommendations for the conduct of economic evaluations in osteoporosis: Outcomes of an experts' consensus meeting organized by the European Society for Clinical and Economic Aspects of Osteoporosis, Osteoarthritis and Musculoskeletal Diseases (ESCEO) and the US branch of the International Osteoporosis Foundation. Osteoporosis International. 2019; 30(1):45-57. https://doi. org/10.1007/s00198-018-4744-x. PMid:30382319, PMCid: PMC6331734.

14. Zheng K, Makrogiannis S. Bone Texture Characterization for Osteoporosis Diagnosis using Digital Radiography. In: 2016 38th Annual International Conference of the IEEE
Engineering in Medicine and Biology Society (EMBC) 2016; p. 1034-37. https://doi.org/10.1109/EMBC.2016.7590879. PMCid: PMC5365038.

15. Jiang $\mathrm{XD}$. Hormone therapy for the treatment of postmenopausal osteoporosis: Will it soon become a lost art in medicine? Menopause. 2018; 25(7):723-27. https://doi. org/10.1097/GME.0000000000001124. PMid: 29738419.

16. Chiodini I, Bolland MJ. Calcium supplementation in osteoporosis: useful or harmful? European Journal of Endocrinology 2018; 178(4):D13-25. https://doi. org/10.1530/EJE-18-0113. PMid: 29440373.

17. Mahdaviazad H, Keshtkar V, Emami MJ. Osteoporosis guideline awareness among Iranian family physicians: results of a knowledge, attitudes, and practices survey. Primary Health Care Research and Development. 2018; 19(5):485-91. https://doi.org/10.1017/S1463423618000014. PMid: 29380714, PMCid: PMC6452934.

18. Weaver CM, Alexander DD, Boushey CJ, Dawson-Hughes B, Lappe JM, LeBoff MS, et al. Calcium plus vitamin D supplementation and risk of fractures: An updated metaanalysis from the National Osteoporosis Foundation. Osteoporosis International. 2016; 27(1):367-76. https://doi. org/10.1007/s00198-015-3386-5. PMid: 26510847, PMCid: PMC4715837. 


\section{Annexure-I}

\section{Consent Form}

As part of our research project we would like to collect data from you and would like to know your opinions about the following:

RESEARCH TITLE: Knowledge, Attitude and Practices towards Osteoporosis among General practitioners working in Majmaah Province, KSA.

Your responses will be kept confidential and will be used only for the purpose of this study. Your participation in this study will be voluntary.If you agree to participate in this study please sign below:

Signature:

Date:

Survey Questionnaire $\left({ }^{*}\right.$ Tick the appropriate answer)

\begin{tabular}{ccc}
\hline Age in years & Years of Experience & Sex \\
\hline $24-35$ & Less than 5 & Male \\
$36-47$ & $5-10$ & Female \\
$48-59$ & More than 10 & \\
More than 60 & & Place of work \\
\hline Nationality & Professional qualification & Doctors in PHC \\
Saudi & MBBS Graduates & Doctors in Hospital \\
Non Saudi & & University doctors \\
\hline
\end{tabular}

1. According to WHO criteria which of the following are the T score to define osteoporosis?
a) Less than -2.5
b) -1.5 to -2.5
c) -0.5 to -1
d) More than -1

2. Which of the following is the Plain X-ray finding in osteoporosis?
a) Decreased intervertebral disc space
b) Increased intervertebral disc space
c) Loss of trabeculae in vertebrae
d) Vertebral end plate sclerosis

3. Which of the following is the most helpful tool for screening patients for osteoporosis?
a) CT scan
b) DEXA scan
c) MRI scan
d) Ultra sound scan

4. Is osteoporosis preventable disease?
a) YES
b) $\mathrm{NO}$

5. According to you, Can Osteoporosis be treated at PHC level or should be referred to higher center?

a) Can be treated at PHC ( )

b) Referred to higher center ( ) 
6. Are you aware of the recent regional guidelines regarding treatment and prevention of Osteoporosis?
a) Aware and following the guidelines
b) Aware but not following the guidelines
c) Not aware of any guidelines

7. Rate the following disease condition depending upon its impact on health of the community and individuals?

\begin{tabular}{l} 
Diseases \\
\hline a) Osteoarthritis \\
b) Osteoporosis \\
c) Coronary heart disease \\
d) Diabetes millets \\
e) Cerebrovascular diseases
\end{tabular}

8. Grade the following risk factors which have a major influence on osteoporosis?

\begin{tabular}{l}
\multicolumn{1}{c}{ Risk factors for osteoporosis } \\
\hline Family history of osteoporosis \\
Post-menopausal Female \\
Lack of physical exercise \\
Poor calcium diet \\
Vitamin D deficiency
\end{tabular}

9. How often do you ask the patient about the following?

\begin{tabular}{llll}
\hline \multicolumn{1}{c}{ History taking } & Very often & Often & Sometimes \\
\hline Back pain & & \\
History of fracture & & \\
Family history of osteoporosis & & \\
Current cigarette smoking & & \\
Daily calcium intake in diet & & \\
\hline
\end{tabular}

10. How often do you look for the following in your examination?

\begin{tabular}{|c|c|c|c|c|}
\hline Physical examination & Very often & Often & Sometimes & Never \\
\hline \multicolumn{5}{|l|}{ Kyphosis } \\
\hline \multicolumn{5}{|l|}{ Loss of height } \\
\hline Low body weight & & & & \\
\hline
\end{tabular}

11. Which one of the following is the first line of pharmacological treatment in majority of patients with Osteoporosis?
a) Bisphosphonates therapy
b) Oral Calcium supplementation
c) Vitamin D injections
d) Hormone replacement therapy 
12. In osteoporosis prevention, Grade the effectiveness of various tools.

Preventive measures

Grading $(5,4,3,2$ and 1 depending upon effectiveness)

Hormone replacement

Calcium supplementation

Vitamin D supplementation

Regular physical exercise

Calcium rich diet

13. Do you have access to perform Bone Mineral Density?
a) YES
b) $\mathrm{NO}$

14. Do you have access to biochemical marker testing of bone?

a) YES

b) $\mathrm{NO}$

15. Are you having any subscription in any medical journal or website?

a) YES

b) $\mathrm{NO}$ 